\title{
Subjetividade docente na perspectiva escolar: memórias de professoras do
}

\section{Distrito Federal}

\section{Teaching subjectivity in the school perspective: memories of teachers of Distrito \\ Federal}

\author{
Katilen Machado Vicente Squarisi, Inês Maria Marques Zanforlin Pires de Almeida \\ Universidade de Brasília, Brasil
}

\begin{abstract}
Resumo
Este artigo apresenta resultados de pesquisa a respeito da constituição do sujeito professor em situação de trabalho. A reflexão parte de escritos sobre suas memórias como dispositivo chamado "Memória Educativa". A leitura e interpretação levou à dramatização de cenas por eles narradas. A partir de uma perspectiva psicanalítica, traz à tona a dimensão do infantil como categoria permitindo compreender o lugar da constituição subjetiva do professor em seu ofício. Quando os professores problematizam sobre sua prática pedagógica pelo pensamento da experiência freudiana num contexto mais amplo, favorecem o resgatar das capacidades de "criar" e libertar-se dos modismos metodológicos.

Palavras-chave: subjetividade docente, ensinoaprendizagem, memória educativa, infantil, psicanálise.
\end{abstract}

\begin{abstract}
This paper presents research results about the constitution of the subject teacher in a work situation. The reflection starts from writings about his memories as a device called "Educational Memory". The reading and interpretation led to the dramatization of scenes narrated by them. From a psychoanalytic perspective, it brings to the fore the dimension of the child as a category, allowing to understand the place of the subjective constitution of the teacher in his or her craft. When teachers problematize their pedagogical practice by thinking Freudian experience in a broader context, they favor the rescue of the capacity to "create" and free themselves from the methodological idioms.

Keywords: Teaching subjectivity, teaching-learning, educational memory, children, psychoanalysis
\end{abstract}

\section{Introdução}

Desde a ancestralidade os humanos produzem registros, "marcas" de memória da sua vida e acontecimentos. Reverenciada na histórica Grécia os gregos reconhecem Mnemosyne (deusa da memória), que perpetuada em diferentes períodos alcança a contemporaneidade e se inscreve fundante na constituição do sujeito como enigma a ser decifrado.

A genialidade de Freud está em ele haver compreendido que, para aprender as causas secretas que movem um ser, que movem esse outro que sofre e a quem escutamos, é preciso, primeiro e acima de tudo, descobrir essas causas em si mesmo, voltar a si - sempre mantendo contato com outro que está diante de nós - o caminho que vai de nossos próprios atos a suas causas (Nasio, 1995, p.12).

Fundamentado no questionamento de como o professor compreende o significado da dimensão do infantil em sua constituição subjetiva e as possíveis repercussões no ofício docente e com o objetivo de esclarecer a dimensão do infantil na constituição da subjetividade de professores à luz da teoria psicanalítica, esse trabalho aponta caminhos para um novo olhar sobre a constituição deste humano que nos habita.

Segundo a teoria Psicanalítica, o infantil é tema significativo na constituição da subjetividade, por sua implicação no consciente do sujeito e do próprio modo de funcionamento de seu inconsciente. O conceito de infantil, coloca-se como campo de ligação. Nele confluem a estrutura como campo de possibilidades definido a partir de uma história, recuperado a partir do não-tempo do inconsciente (Tanis, 1995, p.46).

Em se tratando da noção do infantil Pontalis questiona (Nouvelle revue de Psychanalyse, 1979) ... “acaso a psicanálise não é, em seu próprio princípio, tanto na teoria quanto na prática, inteiramente movida pela crença, sempre confirmada, de que aquilo que chamamos "adulto"- é modelado de uma ponta a outra pelos conflitos, traumas, fantasias e desejos da criança?."

O campo do infantil começa a se configurar em Freud a partir de uma interrogação etiológica sobre a neurose. É nesse contexto que o infantil se relaciona principalmente com a dimensão traumática das experiências da criança ou do adolescente (Tanis, 1995, p.18).

Para Freud, os registros mnêmicos de experiências infantis incapazes de tradução, que não tem acesso à consciência como tais, acaba originando as patologias neuróticas. $\mathrm{Na}$ fase adulta, o infantil continua ativo inconscientemente, influenciando na forma de amar, de se relacionar com o próximo, de lidar com o não afeto do outro e de trabalhar no exercício de sua profissão (Almeida, Kupfer, 2011, p.27).

\section{Metodologia}

Foi ofertado aos docentes de uma escola pública do Distrito Federal, o curso: O lugar do infantil na memória educativa: implicação e reflexão em escrita e ação. A partir da análise das falas de dezenove professoras e da 
escrita de suas memórias, procurou-se identificar possíveis implicações da atuação do professor de educação das séries iniciais do ensino fundamental na constituição da subjetividade infantil e, sobretudo, as possíveis repercussões no ofício docente. A pesquisa pautada pela perspectiva metodológica qualitativa utilizou a memória educativa, observações, entrevistas semiestruturadas e oficinas de sociopsicodrama. Entendeu-se que a memória como dispositivo traz a trajetória das vivências escolares de professoras desde a Educação Infantil até se tornar educador. Percebeu-se, ainda, o efeito da relação do sujeito na aprendizagem, bem como sua subjetividade e vivências, sobretudo, o quanto é importante o educador reconhecer-se nesse processo, vislumbrando o infantil que o constitui

Pensar o lugar da memória educativa é necessário a partir do reconhecimento da escrita como cerne do sujeito, constitutiva de prenúncios que nos enunciam e remetem ao que somos.

Lajonquière (2010) diz que a escrita é posterior à fala, mas não por isso é derivação reduplicada daquela que aconteceu primeiro no tempo. Se, por um lado, ele afirma não se escreve como se fala, fato reconhecido hoje até pela quase totalidade dos estudos psicolinguísticos e pedagógicos, por outro, não lembramos de quando começamos a falar uma língua chamada, curiosamente, materna. Porém guardamos certas lembranças de nossa labuta mais ou menos escolar com as letras e a escrita. Em suma, há um plus na escrita com respeito à fala (Lajonquière , 2010, p.233).

Em muitos momentos percebemos o quanto nossos traços de memória comparecem, influenciando a maneira de agir e ser. Somos feitos de memória, algumas esquecidas; outras, presentes; algumas fantasiosas do desejo ou não.

Neste sentido, partir dos argumentos apresentados de que devemos recuperar uma história das origens relacionadas à emergência da noção de inconsciente, também ressaltamos que o ato de escrever memórias pode adquirir um sentido de inscrição. O sujeito vai se inscrevendo na ordem discursiva na medida em que procura dar conta de uma história que lhe é anterior, "constituindo-se" e recuperando as relações originárias, deparando-se com o lugar do infantil (Almeida, Bareicha, 2015, p.2).

Assim pensando, compreendemos que o professor passou muito tempo em contato com seus professores como aluno, assim como com os colegas, conteúdos e rituais específicos que moldaram o processo de ensinoaprendizagem e a singularidade como docente. $\mathrm{O}$ resgate dessa memória educativa promove uma reflexão da identidade, possibilitando o autoconhecimento de maneira que também se torna possível uma ressignificação e reestruturação da própria história individual e das relações sociais que fazem parte do cotidiano do sujeito (Almeida,1999, p.121).

\section{A dimensão da ação na constituição do sujeito}

Do lugar do sociodrama criado por Moreno, são geradas várias vertentes. De acordo com o interesse da realização, são formas de aplicar o método com influência psicanalítica. Bareicha (1999) remete à postura fenomenológica e existencial, com ênfase nas relações interpessoais, questões grupais, estéticas e transpessoais, enfatizando o pressuposto de que cada sujeito possui uma individualidade única.

O trabalho psicodramático, como aborda Monteiro, Merengué e Brito (2006) é feito de imersão e compreensão. A imersão pressupõe o abrir mão de qualquer certeza, de qualquer conhecimento e se lançar no desconhecimento, no não saber. É preciso, entretanto, ter um fio que o sustente, que ligue o pesquisador ao real, ao objetivo. Com isso ele pode, concretamente, elaborardando sentidos à experiência dramática vivida a compreensão.

Em educação o sociodrama, foi introduzido em settings educacionais de todos os níveis, com o objetivo principal de desenvolver e cultivar a criatividade e espontaneidade de alunos/estudantes, possibilitando que eles se tornem agentes do próprio aprendizado. Silva (2008) mostra que o intuito, nesse caso, não é o de explorar conteúdos privados e internos dos participantes, mas expandir a consciência sobre certos assuntos e promover o desenvolvimento e o crescimento de papéis profissionais. $\mathrm{Na}$ aprendizagem percebemos o quanto é importante o explorar com o olhar voltado para o significante do que se fez aparecer ou não e a partir desse trabalhar para o conhecimento significativo.

As elaborações de Freud em "Lembranças encobridoras" (1899/1980) são reconhecidamente inspiradoras no que diz respeito a memória e lembranças da infância, trazendo a inscrição do infantil no psiquismo.

Ninguém contesta o fato de que as experiências dos primeiros anos de nossa infância deixam traços inerradicáveis nas profundezas de nossa mente. Entretanto, ao procurarmos averiguar em nossa memória quais as impressões que se destinaram a influenciar-nos até o fim da vida, o resultado é, ou absolutamente nada, ou um número relativamente pequeno de recordações isoladas, que são frequentemente de importância duvidosa ou enigmática. É somente a partir do sexto ou sétimo ano- em muitos casos, só depois dos dez anos- que nossa vida pode ser reproduzida na memória como uma cadeia concatenada de eventos. Daí em diante, porém, há também uma relação direta entre a importância psíquica da experiência e sua retenção na memória. (Freud, 1980, p.254)

Como conceito de "lembrança encobridora", Freud remete aquela que deve seu valor enquanto lembrança não a seu próprio conteúdo, mas às relações existentes entre esse conteúdo e algum outro que tenha sido suprimido. Nossas primeiras lembranças infantis serão sempre um tema de especial interesse, pelo fato de as impressões de maior importância para todo o nosso futuro geralmente não deixarem quaisquer imagens mnêmicas atrás de si, levando-nos a refletir sobre a origem das lembranças conscientes em geral.

Freud diz que nossas lembranças infantis nos mostram nossos primeiros anos não como eles foram, mas tal como apareceram nos períodos posteriores em que as lembranças foram despertadas. Nesses períodos de despertar, as lembranças infantis não emergiram, como as pessoas costumam dizer; elas foram formadas nessa 
época. E inúmeros motivos, sem qualquer preocupação com a precisão histórica, participaram de sua formação, assim como da seleção das próprias lembranças.

Neste sentido podemos pensar que o aprender implica de certo modo com atividade em contexto específico, relacionado ao local, ao momento, às pessoas envolvidas e às condições, ou seja a relação com o saber é além de relação com o mundo em um sentido geral. É também relação com esses mundos particulares, meios, espaços nos quais se vive e aprende.

Não se pode negar a dimensão subjetiva do homem, esta que se faz presente, ou se atualiza nas atitudes humanas. A subjetividade, portanto, retira o homem da perspectiva biologizante que desconsidera o inconsciente como um importante componente que, no entanto, só se torna presente por meio da dimensão simbólica, da palavra, esse dom e campo privilegiado (Lacan, 1958, p.347).

\section{Considerações finais}

Por fim, o encontro entre o que foi ensinado e a subjetividade de cada um é que possibilita a aprendizagem, gerando novos conhecimentos. Desejante realidade seria o olhar sensível do professor respeitando a individualidade acima de seu suposto saber.

É possível vislumbrar a importância da escrita da memória educativa, constituindo o sujeito em seu processo educativo trazendo marcas que remontam o infantil presente em todo processo subjetivo. Somos feitos daquilo que se foi e que insiste em se fazer presente.

Freud(1976), traz a medida que o professor se coloca como alguém que não é o dono do saber, nem de todas as certezas absolutas, o educador está identificado na relação pedagógica com o aluno. A aquisição do conhecimento depende estreitamente da relação do aluno com seus professores. Os educadores investidos da relação afetiva primitivamente dirigida aos pais se beneficiarão da influência que este último exercia sobre a criança e poderão desse modo contribuir para a formação do ego ideal dessa criança.

Hannah Arendt no livro "A condição humana” de 1958, aponta que não somos autores de nossa vida, história. $\mathrm{O}$ indivíduo não é seu próprio criador. Ele é condicionado por um conjunto de elementos que contribuem para sua fabricação e sua subjugação. Desse modo, a psicanálise evidencia que somos resultado e expressão de nossa história de vida. Não somos autores nem senhores de nossa história, mas efeitos dela (Chauí, 2000, p.27).

Importante ressaltar a interferência das vivências sociopsicodramáticas que se fizeram fundantes na análise de dados em que o dispositivo da memória educativa, juntamente com a vivência, fez que percebêssemos os processos de identificação e transferência. Aí, o vínculo didático reforça o ser infantil e o sujeito em sua singularidade.

Este trabalho nos permitiu reconhecer o "quantum" do infantil emerge e se presentifica no processo educativo pela via transferencial regada de marcas subjetivas, clareando a relação do sujeito no processo de aprendizagem com sua subjetividade-vivências e quanto é importante para o educador compreender esse processo através do aporte psicanalítico vislumbrando o infantil que o constitui, lançando um outro olhar sobre si mesmo e as marcas que o constituíram como sujeito, de certa forma libertando-se de amarras permitindo que possa Criar ao ensinar como dever e seus alunos aprenderem por Amor!

\section{Referências}

Almeida, Inês; Bareicha, Paulo. Da escrita à inscrição: o lugar do infantil na constituição subjetiva do professor. Congres International Psychanalyse. Et Education, Paris, 2015.

Almeida, Sandra. A psicanálise e os impasses da educação. São Paulo. Lugar de Vida / Lepsi, 1999.

Almeida, Sandra; Kupfer, Maria (Orgs.) A psicanálise e $o$ trabalho com a criança-sujeito. $1^{\circ}$ edição Rio de Janeiro: Wak, 2011.

Bareicha, Paulo. Psicodrama, teatro e educação: em busca de conexões. Linhas Críticas, v. 4, n. 7-8, 1999.

Chauí, Marilena. Convite à Filosofia. São Paulo: Ática, 2000.

Freud, Sigmund. Cinco lições de Psicanálise. In Obras psicológicas completas de Sigmund Freud. Edição standard brasileira. Rio de Janeiro: Imago, v. VII, 1976[1913].

Freud, Sigmund. Extratos dos documentos dirigidos a Fliess. In Edição Standard Brasileira das Obras Psicológicas completas de S. Freud. Rio de Janeiro: Imago, v. 1, 1980. 243-380 p.

Lacan, Jacques. O seminário, livro 5: As formações do inconsciente. Rio de Janeiro: Zahar, 1958/1999.

Lajonquière, Leandro. Figuras do Infantil: a Psicanálise na vida cotidiana com as crianças. Petrópolis: Vozes, 2010.

Monteiro, André; Merengué, Devanir; Brito, Valéria. Pesquisa quantitativa e psicodrama. São Paulo: Ágora, 2006.

Nasio, Juan-David. Introdução às obras de Freud, Rio de Janeiro, Zahar, 1995.

Silva, Helena. Sociodrama: um espaço de refúgio, liberdade e criatividade! Contributos da metodologia sociodramática na formação de educadores sociais. Revista Brasileira de Psicodrama, v. 16, n. 2, p. 87-100, 2008.

Tanis, Bernardo. Memória e temporalidade, São Paulo, Casa do Psicólogo, 1995.

\section{Adradecimentos}

Com menção de agradecimento à Fundação de Apoio à Pesquisa - FAP/DF. 